УДК 624.131 .412

\title{
ВЛИЯНИЕ ДАВЛЕНИЯ НА СТРУКТУРУ КАОЛИНИТА В ОГНЕУПОРНЫХ ГЛИНАХ НИЖНЕ-УВЕЛЬСКОГО МЕСТОРОЖДЕНИЯ ПО ДАННЫМ ИК-СПЕКТРОСКОПИИ
}

\author{
Ситева Ольга Сергеевна ${ }^{1}$, \\ sisesin@rambler.ru
}

\author{
Медведева Наталья Александровна², \\ nata-kladova@yandex.ru
}

Середин Валерий Викторович2, seredin@nedra.perm.ru

\author{
Иванов Дмитрий Владимирович2, \\ dm-psu@yandex.ru

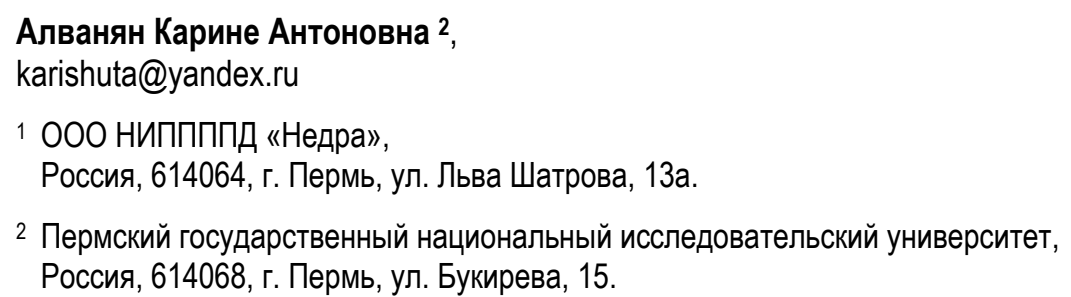

Актуальность исследования обусловлена необходимостью изучения структуры каолиновых глин в связи с их широким промышленным применением. Физические и физико-химические свойства глин изменяются при различных техногенных воздействиях на них, что обусловлено преобразованием кристаллической структуры.

Цель: изучение влияния давления на структуру каолинита.

Объект: каолиновая глина Нижне-Увельского месторождения Челябинской области.

Метод: инфракрасная спектроскопия. Инфракрасные спектры регистрировались на ИК Фурье-спектрометре в интервале 400...3800 см-1. Обработка ИК-спектров проводилась с помощью программного обеспечения Fspec.

Результаты экспериментальных исследований показали, что обогащенная каолиновая глина Нижне-Увельского месторождения Челябинской области, не подверженная воздействию давлением, характеризуется частично упорядоченной (дефектной) структурой. При воздействии давлений от 10 до 650 МПа глина характеризуется частично упорядоченной структурой, при давлениях от 700 до 800 МПа - слабо и неупорядоченной структурой. Обработка каолина давлением повышает дефректность структуры на уровне пакета. Связи между Al-OH, Si-O-Al, внутренними и внутриповерхностными гидроксилами разрушаются, что приводит к вытеснению Al из октаэдрического и Si из тетраэдрического листов и формированию «дырочных» энергетических центров в кристаллической решетке каолинита. При этом влияние давления до 150 МПа на формирование десректов в каолините выше, чем при давлениях от 150 до 800 МПа. Кроме того, при обработке каолина давлением происходит образование дефектов структуры на межпакетном уровне за счет скольжения, вращения и прокатки структурных пакетов между собой.

\section{Ключевые слова:}

Огнеупорная глина, месторождение, каолинит, модификация, инфракрасная спектроскопия, степень совершенства структуры.

\section{Введение}

В настоящее время в связи с широким промышленным применением глин многие исследователи работают над модификацией природных алюмосиликатов для улучшения их поверхностных свойств. К таким свойствам относятся: лиофильность, сорбционная способность, ионный обмен, которые зависят не только от дисперсности грунтов, но и от особенностей реального строения их кристаллической структуры $[1,2]$.

Наибольшей изменчивостью совершенства (дефектности) структуры среди глинистых минералов обладают минералы группы каолинита [3], хотя кристаллическая решетка минералов этой группы самая простая. Она представляет собой двухслойные пакеты типа $1: 1$, где чередуются октаэдрические и тетраэдрические слои.

Структурная упорядоченность каолинитов обуславливает поверхностные свойства глинистых ча- стиц при взаимодействии с жидкими и газообразными средами. Их лиофильность, в свою очередь, определяет степень применения каолиновых глин в качестве огнеупорного сырья в промышленности.

Совершенство структуры природных глин определяется их генезисом. Различают два основных типа каолинов: первичные и вторичные. По данным [4] первичные каолины (элювиальные) являются конечным продуктом выветривания магматических и метаморфических пород, которые остаются на месте своего образования. Вторичные каолины (осадочные или переотложенные) являются производными первичных каолинов. Они образуются вследствие размыва и переотложения в водной среде продуктов каолинового выветривания. Высокая степень совершенства кристаллической структуры характерна для каолинитов, составляющих первичные каолины, низкая - для вторичных каолинов [4]. 
Согласно Ю.А. Русько [5], под «степенью упорядоченности» каолинита понимается относительная мера нарушения строгой периодичности реальной исследуемой структуры, вызванная дефектами внутреннего строения отдельных слоев и главным образом неупорядоченностью их взаимного расположения По мнению Ф.Д. Овчаренко и др. [4], наиболее распространенный тип дефектов структуры каолинита обусловливается неупорядоченностью наложения последующих двухэтажных каолинитовых слоев, приводящей к их возможному смещению, а также отклонением формы элементарной ячейки каолинита от триклинной, вызванным нарушением упорядоченности внутри слоя. При многочисленных нарушениях такого характера слои могут располагаться с образованием моноклинной ячейки. По данным, указанным в работах Э.П. Солотчиной и др. [6] и М.А. Пластининой, Е.Г. Куковского [7], основным дефектом упаковки слоев является простое смещение вакансии октаэдрических мест от одного слоя к другому или же от одной области одного и того же слоя к другой.

При определении степени совершенства структуры каолинита в основном используется метод Хинкли Индекс Хинкли, определяемый по дифрактограммам, варьируется от 1,65 для вполне упорядоченных каолинитов до нуля для неупорядоченных [4].

При изучении глинистых минералов и совершенства структуры каолинитов также используется инфракрасная (ИК) спектроскопия. На колебательный спектр каолинитов оказывают влияние: механическое измельчение [8-12], термическая обработка [9, 13], обработка кислотами и щелочами [14], воздействие давлением $[3,12]$.

При механическом измельчении происходит ослабление интенсивностей полос поглощения и расширение полос ОН-групп и $\mathrm{Si}-\mathrm{O}$. Структура каолинита становится менее совершенной, вплоть до рентгеноаморфного состояния. При термической обработке происходит процесс дегидратации, который затем сменяется на дегидроксилирование, при этом происходит уменьшение интенсивностей колебаний всех гидроксильных групп. При воздействии кислоты и щелочи на хорошо упорядоченный каолинит интенсивность пиков в целом сохраняется, а вот у слабо упорядоченного она падает. При обработке каолинита кислотой также образуется аморфный кремний и происходит выход $\mathrm{Al}$ из октаэдрического слоя.

По опытным данным В.А. Дрица [3] в одних и тех же условиях под давлением в 5-10 тс/см несовершенные каолиниты становятся рентгеноаморфными, в то время как каолиниты с совершенной структурой выдерживают подобную обработку без существенных изменений. По работам М.А. Пластининой и др. [12] при воздействии давления $686 \cdot 10^{6} \mathrm{H} / \mathrm{M}^{2}$ на каолиниты индекс кристалличности Хинкли уменьшался от 1,2 до 0,65 , в то время как в ИК-спектре положение, форма и интенсивность полос поглощения не изменились. Авторы предположили, что механизм действия давления заключается в параллельном смещении слоев и не затрагивает энергетического взаимодействия связей в слое. При испытании каолинитов различного генезиса (первичные и вторичные каолины) и месторождений могут быть получены другие показатели в зависимости от совершенства кристаллической структуры.

Таким образом, вопросы оценки дефектности структуры каолиновой глины, подверженной техногенной обработке, изучены недостаточно полно, поэтому целью работы является исследование влияния давления на структуру каолинита в глине НижнеУвельского месторождения.

\section{Объект исследования}

Объектом исследования являлась обогащенная глина на основе каолинов, добываемых Челябинским рудоуправлением на Нижне-Увельском месторождении. Данное месторождение огнеупорных глин находиться в непосредственной близости от ст. НижнеУвельской Южноуральской железной дороги, в 5 км от г. Южноуральска, в 40 км к северу от г. Троицка Челябинской области. Обзорная геологическая схема представлена на рис. 1.

Залежи глин приурочены к озерно-аллювиальным отложениям наурзумской свиты миоцена. Мощность свиты составляет от 2 до 20 м. Особенности состава пород наурзумской свиты определены тем, что, с одной стороны, материалом для их формирования служили зрелые образования коры выветривания, а с другой - тем, что в условиях влияния климата этот материал претерпел при переотложении существенные преобразования. Добыча на месторождении ведется открытым способом, послойно и селективно. Глины широко используются как огнеупорное, формовочное и керамическое сырье.

Гранулометрический состав природной и обогащенной глин, исследуемых в работе, приведен в табл. 1.

Таблица 1. Гранулометрический состав природной и обогащуенной каолиновой глинь

Table 1. Granulometric composition of natural and enriched kaolin clay

\begin{tabular}{|c|c|c|c|c|c|}
\hline \multirow{2}{*}{$\begin{array}{c}\text { Глина } \\
\text { каолиновая } \\
\text { Kaolin clay }\end{array}$} & \multicolumn{5}{|c|}{$\begin{array}{c}\text { Содержание частиц во фракциях, \% } \\
\text { Content of particles in fractions, \% }\end{array}$} \\
\cline { 2 - 6 } & $0,25-0,1$ & $0,1-0,05$ & $0,05-0,01$ & $0,01-0,005$ & $<0,005$ \\
\hline $\begin{array}{c}\text { Природная } \\
\text { Natural }\end{array}$ & 0,3 & 9,5 & 30,2 & 15,5 & 44,5 \\
\hline $\begin{array}{c}\text { Обогащенная } \\
\text { Enriched }\end{array}$ & - & - & 7,7 & 7,8 & 84,5 \\
\hline
\end{tabular}

По результатам рентгеноструктурного анализа обогащенная глина содержит: каолинит (76,7 \%), монтмориллонит (15,6 \%), кварц $(7,7 \%)$ [15].

\section{Методика}

Подготовка образцов включала в себя обогащение природного каолина и обработку его давлением.

Обогащение природного Челябинского каолина осуществляли методом седиментации для увеличения процентного содержания тонкодисперсной фракции размером менее 0,005 мм. Полученная таким образом глина была высушена и перетерта в порошок. Часть порошка массой около 0,2 г помещалась в рабочую зону специально изготовленного прибора высокого 
давления [15], рабочие поверхности которого выполнены из твердосплавного материала. После чего прессом подавались вертикальные давления на образец грунта. В качестве нагрузочного устройства использовался пресс марки ПЛГ-20. Каждый образец уплотнялся под определенным давлением от 10 до 800 МПа. Давление выдерживалось 1 минуту. В результате сжатия и сдвига получены образцы в форме «таблеток» площадью $0,75 \mathrm{~cm}^{2}$.
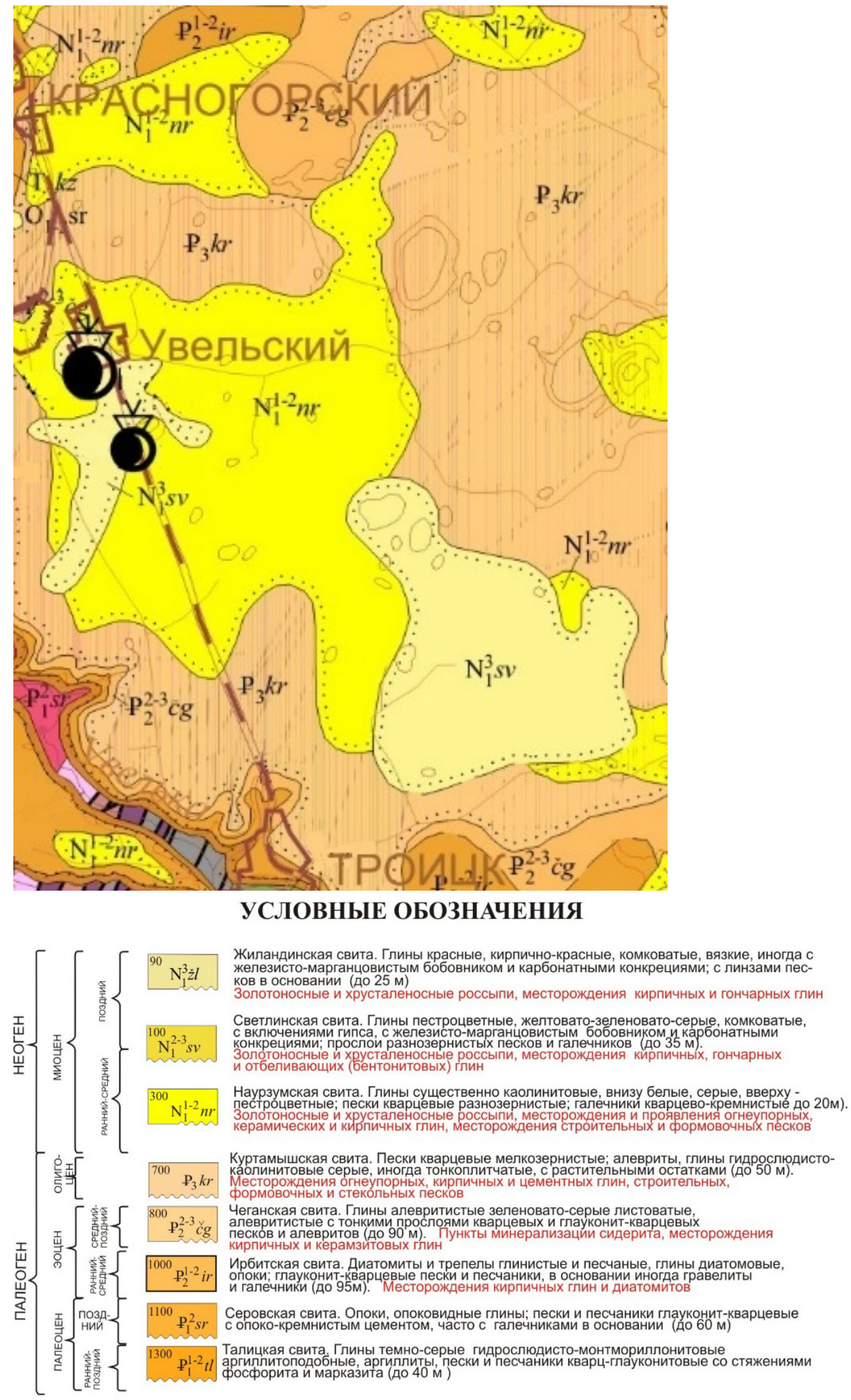

Рис. 1. Обзорная геологическая схема (по Б.А. Пужакову и др., 2010 г.)

Fig. 1. Survey geological scheme (according to B.A. Puzhakov et al., 2010) 
Для инфракрасной спектроскопии образцы глины в виде «таблеток» растирались до порошка (массой не более $0,5-2$ мг), затем смешивали с вазелиновым маслом для создания однородного распределения частиц в луче. Полученную однородную пасту аккуратно наносили на солевое окно $\mathrm{KBr}$ и раздавливали в тонкий слой вторым окном [16-18].

Вазелиновое масло имеет сильное поглощение в области деформационных (1350-1500 см $\left.{ }^{-1}\right)$ и валентных $\left(2700-3000 \mathrm{~cm}^{-1}\right)$ колебаний СН-связей. Согласно литературным данным [19], в данных областях не наблюдаются пики поглощения, характерные для глинистых минералов.
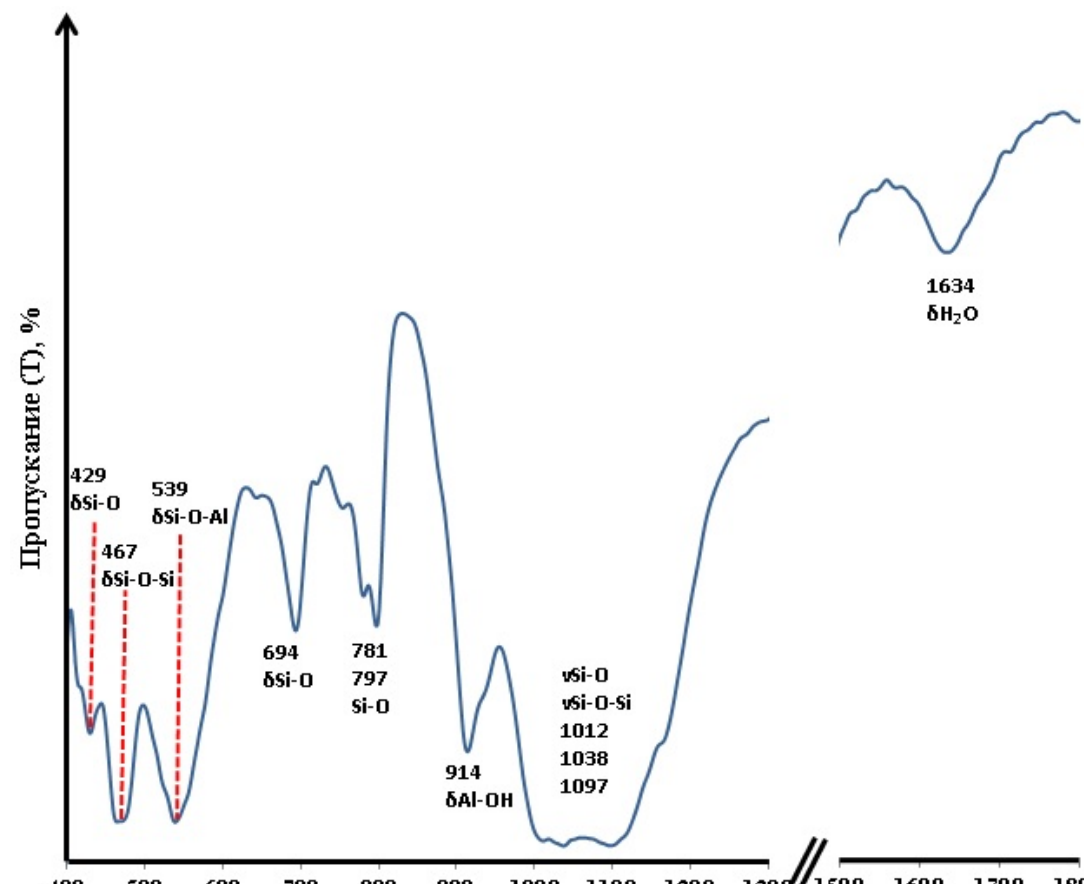

Структура исходного каолина

Для обогащенного образца каолина, не подверженного давлению, получен инфракрасный спектр от 400 до $3800 \mathrm{~cm}^{-1}$, который представлен на рис. 2. фраспек» в интервале $400 \ldots 3800 \mathrm{~cm}^{-1}$ с разрешением $2 \mathrm{~cm}^{-1}$ (FT-IR), с помощью программного обеспечения Fspec [18].

\section{Результаты и обсуждения}

Инфракрасные спектры регистрировались на ИК 
за исключением колебаний внутриповерхностных ОН-групп, которые отсутствуют в монтмориллоните.

В табл. 2 приведено сравнение полученных нами экспериментальных данных с данными по литературному обзору [19-28].

Из таблицы видно, что полосы поглощения, полученные нами, сопоставимы с опубликованными данными [19-28].

Из чего следует, что для обогащенной каолиновой глины, не обработанной давлением, выявлены полосы поглощения, которые не противоречат литературным данным.

\section{Влияние давления на изменение структуры каолинита}

Воздействие давлением на образцы каолина приводит к тому, что на инфракрасных спектрах наблюдается снижение интенсивностей полос пропускания всех связей и уширение некоторых. На рис. 3, $a$, 6 представлен колебательный спектр в диапазоне волновых чисел $400-1300 \mathrm{~cm}^{-1}$ и $3550-3750 \mathrm{~cm}^{-1}$ отмученных образцов глин, подверженных сжатию при давлениях 150, 200 и 800 МПа. Особое внимание стоит уделить деформационным колебаниям связей $\mathrm{Si}-\mathrm{O}$ $\mathrm{Al}, \mathrm{Al}-\mathrm{OH}$ и, в особенности, валентным колебаниям гидроксильных групп, которые являются чувствительным индикатором совершенства кристаллической структуры каолинита.
Таблица 2. Полосы поглощеения исходного образиа каолина

Table 2. Absorption bands of the original kaolin sample

\begin{tabular}{|c|c|c|}
\hline $\begin{array}{c}\text { Природа } \\
\text { колебаний } \\
\text { Nature } \\
\text { of vibrations }\end{array}$ & $\begin{array}{c}\text { Полосы поглощения } \\
\text { исходного образца } \\
\text { каолинита, } \mathrm{cm}^{-1} \\
\text { Absorption bands of } \\
\text { the original kaolin } \\
\text { sample, } \mathrm{cm}^{-1} \\
\end{array}$ & $\begin{array}{c}\text { Полосы поглощения } \\
\text { по литературным } \\
\text { данным, } \mathrm{cm}^{-1} \\
\text { Absorption bands ac- } \\
\text { cording to the literature } \\
\text { review, } \mathrm{cm}^{-1} \\
\end{array}$ \\
\hline $\begin{array}{l}v \mathrm{OH}_{\text {внутриповерхностные }} \\
v \mathrm{OH}_{\text {inner-surface }}\end{array}$ & $\begin{array}{r}3696 \\
3672 \\
3654 \\
\end{array}$ & $\begin{array}{l}3705-3690 \\
3671-3663 \\
3652-3650 \\
\end{array}$ \\
\hline $\begin{array}{l}\mathrm{vOH} \mathrm{OH}_{\text {внутренние }} \\
\mathrm{vOH}_{\text {inner }}\end{array}$ & 3621 & $3635-3620$ \\
\hline$v \mathrm{H}_{2} \mathrm{O}$ & 3426 & $3440-3416$ \\
\hline$\delta \mathrm{H}_{2} \mathrm{O}$ & 1634 & $1605-1650$ \\
\hline$v \mathrm{Si}-\mathrm{O}$ & 1097 & $1115-1100$ \\
\hline$v \mathrm{Si}-\mathrm{O}-\mathrm{Si}$ & $\begin{array}{l}1038 \\
1012\end{array}$ & $\begin{array}{l}1037-1033 \\
1012-1002\end{array}$ \\
\hline$\delta \mathrm{Al}-\mathrm{OH}$ & 914 & $\begin{array}{l}940-935 \\
918-915 \\
\end{array}$ \\
\hline $\begin{array}{l}\text { Si-O (кварц дуб- } \\
\text { лет) } \\
\text { Si-O (quartz } \\
\text { doublet) }\end{array}$ & $\begin{array}{l}797 \\
781\end{array}$ & $\begin{array}{l}797 \\
779\end{array}$ \\
\hline$\delta \mathrm{Si}-\mathrm{O}$ & 694 & $695-694$ \\
\hline$\delta \mathrm{Si}-\mathrm{O}-\mathrm{Al}$ & 539 & $545-510$ \\
\hline$\delta \mathrm{Si}-\mathrm{O}-\mathrm{Si}$ & 467 & 470 \\
\hline$\delta \mathrm{Si}-\mathrm{O}$ & 429 & $433-425$ \\
\hline
\end{tabular}
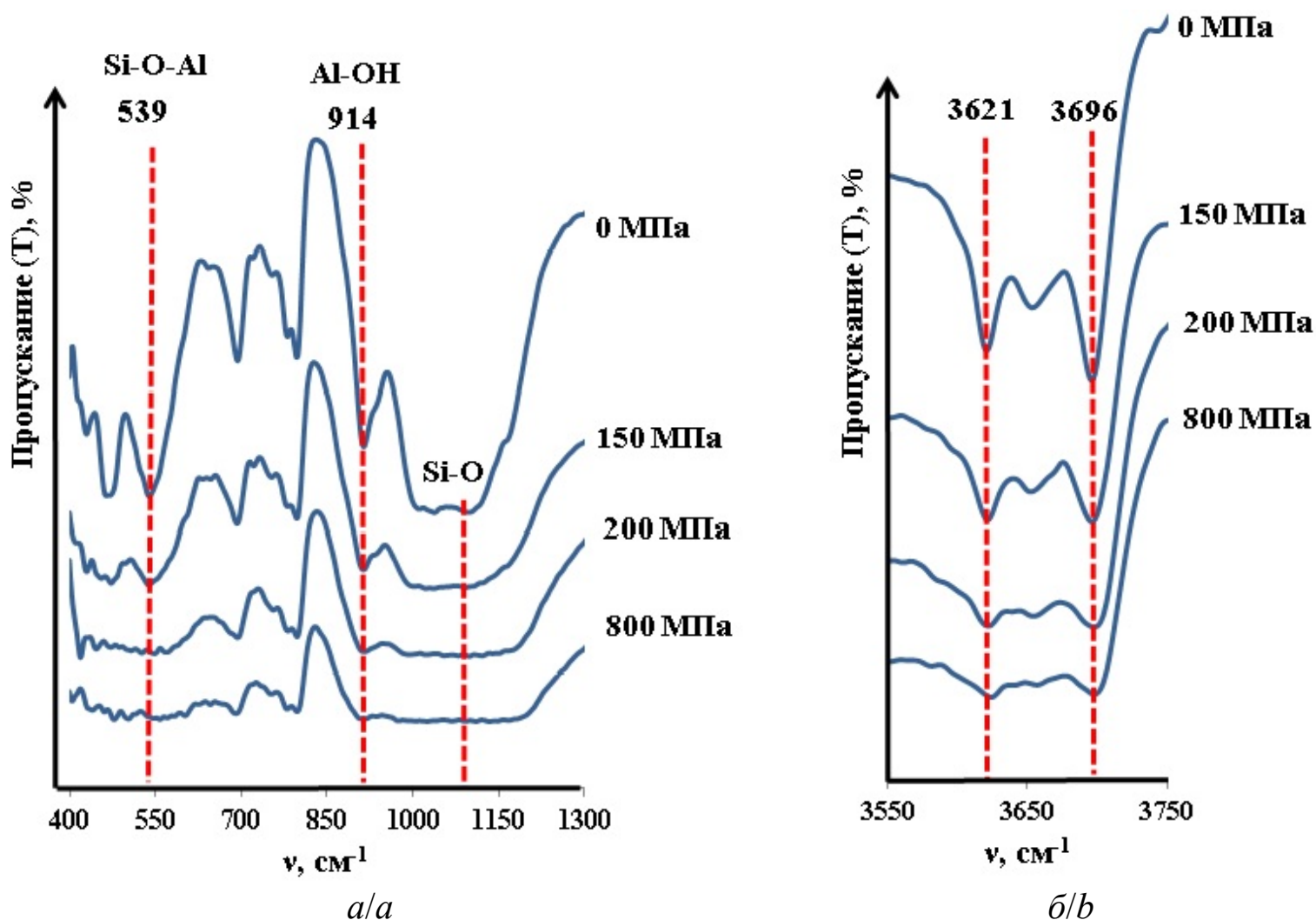

Рис. 3. Инфракрасный спектр образиов каолина, подверженных сжатию, в диапазоне волновых чисел $400-1300 \mathrm{~cm}^{-1}$ (a) $u 3550-3750 \mathrm{~cm}^{-1}$ (б)

Fig. 3. Infrared spectrum of kaoline samples subjected to compression in the range of wave numbers $400-1300 \mathrm{~cm}^{-1}$ (a) and $3550-3750 \mathrm{~cm}^{-1}$ (b) 
Из рис. 3, а видно, что полоса колебаний $\mathrm{Si}-\mathrm{O}-\mathrm{Al}$ (максимум которой соответствует волновому числу $\left.539 \mathrm{~cm}^{-1}\right)$ до давления 150 МПа уменьшается, а при давлениях свыше 200 МПа становиться размытой, затем совсем пропадает. Это говорит о нарушении связи и вытеснении $\mathrm{Al}$ из кристаллической решетки каолинита.

Полоса валентных колебаний кремнекислородных групп в области 950-1200 $\mathrm{cm}^{-1}$ также ослабевает и расширяется при увеличении давления. Возможной причиной является искажение самих структурных многогранников в кристаллической решетке минералов (их сплющивание, расширение, разворот и т. д.).

Интенсивность полос колебаний гидроксильных групп Al-OH (с максимумом волнового числа $914 \mathrm{~cm}^{-1}$ ), внутренних гидроксилов $\left(3621 \mathrm{~cm}^{-1}\right)$, внутриповерхностных гидроксилов $\left(3696 \mathrm{~cm}^{-1}\right)$ при возрастании давления также уменьшается. Но в отличие от колебания связи Si-O-Al, эти полосы прослеживаются в инфракрасном спектре при давлениях до 800 МПа.

$\mathrm{y}$ образца каолина при $\mathrm{P}=0 \mathrm{MПа}$ полоса $\mathrm{OH}$ внутриповерхностных гидроксилов $\left(3696 \mathrm{~cm}^{-1}\right)$ более сильная, чем ОН-внутренних гидроксилов $\left(3621 \mathrm{~cm}^{-1}\right)$. Это обусловлено кристаллическим строением минералов группы каолинита. В интервале пороговых давлений 150-200 МПа и выше наблюдается выравнивание интенсивностей двух пиков, что связано с более интенсивным разрывом связей ОН-внутриповерхностных гидроксилов, которые разрушаются в первую очередь при механическом сжатии. Выравнивание интенсивностей ОН-полос 3621 и $3696 \mathrm{~cm}^{-1}$ должно свидетельствовать также о меньшей степени упорядоченности распределения $\mathrm{Al}$ в октаэдрических позициях.

Можно заключить, что при обработке каолина давлением наблюдается изменение (уменьшение) интенсивности полос колебаний и уширение рефлекса (пика) на половине его высоты. Эти изменения можно трактовать, как изменение (увеличение) дефектности структуры минералов группы каолинита. Также обработка каолина давлением может вызывать скольжение, вращение и прокатку структурных пакетов между собой.

Для оценки дефектности структуры каолинита проведен качественный и количественный анализ ИК-спектров.

\section{Оценка степени дефектности структуры каолинита}

Качественная оценка степени совершенства структуры каолинита

По качественному критерию, наличию гидроксильных групп, структуру исходного образца Челябинского каолинита можно охарактеризовать как частично упорядоченную, так как в инфракрасном спектре присутствуют три четких пика колебаний ОНгрупп 3696, 3654, $3621 \mathrm{~cm}^{-1}$ и один слабо выраженный пик $3672 \mathrm{~cm}^{-1}$. Упорядоченный (бездефектный) каолинит имеет все четыре четкие полосы поглощения около $3696,3672,3654$ и $3621 \mathrm{~cm}^{-1}[13,21,28]$.

В каолините, обработанном давлением $\mathrm{P}=10$ 800 МПа, наблюдались существенные изменения полос поглощения гидроксильных групп. При увеличе- нии давления до 125-200 МПа происходит слияние слабого пика $3672 \mathrm{~cm}^{-1}$ и пика $3654 \mathrm{~cm}^{-1}$ в один общий пик, что характерно для частично упорядоченного каолинита. Полоса этого объединенного пика прослеживается до давления $650 \mathrm{MПа,} \mathrm{после} \mathrm{чего} \mathrm{пропа-}$ дает. При более высоких давлениях до 800 МПа выделяются только два пика - около 3696 и $3621 \mathrm{~cm}^{-1}$, что объясняется слабо- и неупорядоченной структурой каолинита.

Следовательно, по качественному критерию при давлениях от 10 до 650 МПа каолинит характеризуется частично упорядоченной структурой, при давлениях от 700 до $800 \mathrm{MПа} \mathrm{-} \mathrm{слабо} \mathrm{и} \mathrm{неупорядоченной}$ структурой.

\section{Количественная оценка степени}

совершенства структуры каолинита

Для количественной оценки совершенства (дефектности) структуры каолинита использовалась высота полос пропускания на ИК-спектрах.

Из рис. 3 видно, что с увеличением давления наблюдается тенденция к уменьшению интенсивности полос пропускания. Так, высота полосы Al-OH уменьшается в 5 раз, $\mathrm{OH}_{\text {внутр }}$ - в 2 раза и $\mathrm{OH}_{\text {внутриповерх }}-$ в 2,5 раза.

Снижение интенсивности свидетельствует о том, что связи между Al-OH, Si-O-Al, $\mathrm{OH}_{\text {внутр, }} \mathrm{OH}_{\text {внутриповерх }}$ в кристаллической решетке каолинита разрушаются. Это приводит к вытеснению Al из октаэдрического и $\mathrm{Si}$ из тетраэдрического листов каолинита. Такое вытеснение формирует «дырочные» энергетические зоны в кристаллической решетке минерала, которые во многом определяют физико-химические свойства глин. При этом влияние давления до $\mathrm{P}=150 \mathrm{MПа} \mathrm{на}$ формирование дефектов в каолините выше, чем давления $\mathrm{P}=150-800 \mathrm{MПа,} \mathrm{что} \mathrm{согласуется} \mathrm{с} \mathrm{ранее} \mathrm{полу-}$ ченными данными [29].

Для оценки степени дефектности используется критерий интенсивности гидроксильных групп $(R)$. Он трактуется следующим образом, чем ниже значение $R$, тем выше дефектность структуры каолинита. Критерий $R$ рассчитывается по формуле:

$$
R=D_{3696} / D_{3621},
$$

где $D$ - оптическая плотность в максимуме полосы поглощения.

Результаты экспериментальных исследований представлены на рис. 4.

Из рис. 4 видно, что с увеличением давления показатель $R$ снижается, то есть дефектность структуры возрастает. Полученные данные согласуются с результатами исследований других авторов $[12,30]$, которые отмечали, что более высокие значения $R$ наблюдаются в каолинах с более совершенной структурой.

В ранее проведенных исследованиях [31] авторы пришли к схожим выводам. Так, по данным рентгеновской дифрактометрии при воздействии давлений до 800 МПа наблюдается уширение рефлексов, в то время как интегральная интенсивность рефлексов уменьшается. Это свидетельствует об увеличении дефектности кристаллической структуры, переходе от 
упорядоченных к неупорядоченным каолинитам и образованию аморфной фазы.

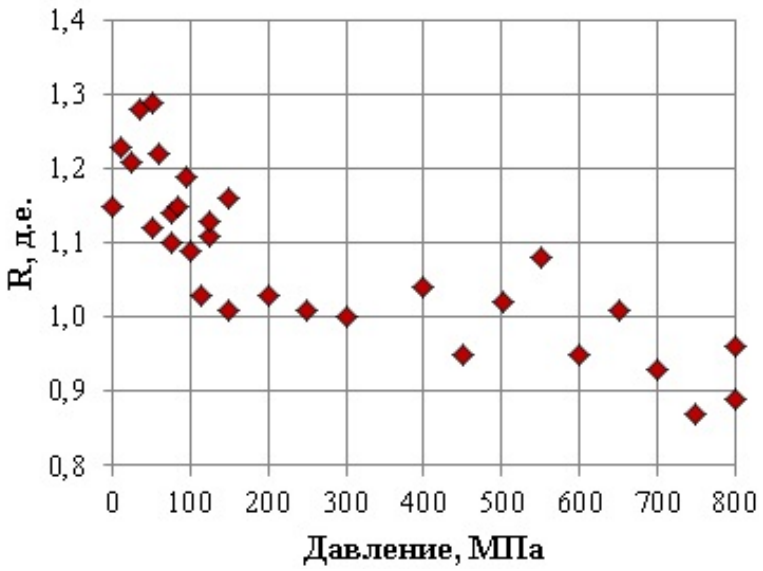

Рис. 4. Изменение отношения интенсивностей полос 3696 u $3621 \mathrm{cM}^{-1}$

Fig. 4. Changes in the intensity ratio of the bands of 3696 and $3621 \mathrm{~cm}^{-1}$

\section{СПИСОК ЛИТЕРАТУРЫ}

1. Куковский Е.Г. Превращения слоистых силикатов. - Киев: Изд-во «Наукова думка», 1973. - 101 с.

2. Медведева Н.А., Ситева О.С., Середин В.В. Сорбционная способность глин, подверженных сжатию // Вестник ПНИПУ. Геология. Нефтегазовое и горное дело. - 2018. - Т. 18. № 2. - C. 118-128. DOI: 10.15593/2224-9923/2018.4.2

3. Дриц В.А. Природа нарушения упорядоченности в структурах некоторых слоистых силикатов // Рентгенография минерального сырья: сб. статей. - 1966. - Вып. 5. - С. 94-105.

4. Каолины Украины / Ф.Д. Овчаренко, Н.Н. Круглицкий, Ю.А. Русько, И.И. Мороз, М.С. Комская, Ю.Н. Теодорович. Киев: Изд-во «Наукова думка», 1982. - 367 с.

5. Русько Ю.А. Структурные и морфологические различия каолинита в породах коры выветривания украинского щита // Каолины. - М.: Изд-во «Наука», 1974. - С.95-106.

6. Солотчина Э.П., Сухоруков Ф.В. О тонкой кристаллической структуре каолинитов коры выветривания на гранитах // Доклады Академии наук СССР. - 1979. - Т. 244. - № 4. - С. 964-968.

7. Пластинина М.А., Куковский Е.Г. Степень совершенства каолинитов по данным рентгенографии и ИК-спектроскопии // Минералогический журнал. - 1979. - Т. 1. - № 2. - С. 67-72.

8. Murray H.H., Lyons S.C. Further correlations of kaolinite crystallinity with chemical and physical properties // Clays Mineralogy. - 1960. - V. 8. - P. 11-17.

9. The effect of micronization on kaolinites and their sorption behavior / G. Suraj, C.S.P. Iyer, S. Rugmini, M. Lalithambika // Applied Clay Science. - 1997. - V. 12. - P. 111-130.

10. Modification of low- and high-defect kaolinite surfaces: implications for kaolinite mineral processing / R.L. Frost, E. Horváth, É. Makó, J. Kristóf // Journal of Colloid and Interface Science. - 2004. - V. 270. - P. 337-346.

11. Вяхирев Н.П. Промежуточные формы в непрерывном ряду аморфное вещество - каолинит// Рентгенография минерального сырья: сб. статей. - 1966. - Вып. 5. - С. 128-131.

12. Некоторые особенности проявления несовершенства каолинитов на их инфракрасных спектрах поглощения / М.А. Пластинина, Е.Г. Куковский, Ю.Г. Федоренко, В.М. Кадошников // Минералогический сборник. - 1979. - № 33. - Вып. 1. - С. 27-32.

13. Тарасевич Ю.И., Овчаренко Ф.Д. Адсорбция на глинистых минералах. - Киев: Изд-во «Наукова думка», 1975. - 351 с.

14. Pentrak M., Madejova J., Komadel P. Acid and alkali treatment of kaolins // Clay Minerals. - 2009. - V. 44. - P. 511-523.

15. Влияние давления на площадь активной поверхности частиц глинистых грунтов / В.В. Середин, А.В. Растегаев, Н.А. Медведева, Т.Ю. Паршина // Инженерная геология. - 2017. № 3. - C. 18-27. DOI: 10.25296/1993-5056-2017-3-18-27.

\section{Выводы}

1. Обогащенная каолиновая глина, не подверженная воздействию давления, характеризуется частично упорядоченной (дефектной) структурой по данным ИК-спектроскопии. При воздействии давлений от 10 до 650 МПа глина характеризуется частично упорядоченной структурой, при давлениях от 700 до 800 МПа - слабо- и неупорядоченной структурой.

2. Обработка каолина давлением повышает дефектность структуры на уровне пакета. Связи Al-OH, $\mathrm{Si}-\mathrm{O}-\mathrm{Al}, \mathrm{OH}_{\text {внутр, }} \mathrm{OH}_{\text {внутриповерх в кристаллической }}$ решетке минералов группы каолинита разрушаются, что приводит к вытеснению $\mathrm{Al}$ из октаэдрического и $\mathrm{Si}$ из тетраэдрического листов и формированию «дырочных» энергетических центров в кристаллической решетке. При этом влияние давления до 150 МПа на формирование дефектов в каолините выше, чем при давлении от 150 до 800 МПа.

16. Кубекова Ш.Н., Танау А. Использование метода ИКспектроскопии для определения молекулярного состава неорганических веществ. Методические указания к лабораторным занятиям. - Алматы: КазНТУ им. К.И. Сатпаева, 2014 - 17 с.

17. Папко Л.Ф., Кравчук. А.П. Физико-химические методы исследования неорганических веществ и материалов. Практикум. Минск: БГТУ, 2013. - 95 с.

18. Специализированный практикум по физико-химическим методам анализа: Теория и практика. Ч. II / А.П. Нечипоренко, С.М. Орехова, Л.В. Плотникова, Е.Н. Глазачева, К.В. Волкова, М.В. Успенская. - СПб.: Университет ИТМО, 2016. - 181 с.

19. Chukanov N.V. Infrared spectra of mineral species. - Dordrecht: Springer, 2014. $-1726 \mathrm{p}$

20. Плюснина И.И. Инфракрасные спектры минералов. - М.: Изд-во Моск. Ун-та, 1976. - 190 с.

21. Уоррел У. Глины и керамическое сырье. - М.: Изд-во «Мир», 1978. $-241 \mathrm{c}$

22. Идентификация минеральных макрокомпонентов неорганической части канско-ачинских углей / А.С. Заворин, К.В. Буваков, В.Е. Гладков, Л.Г. Красильникова // Известия Томского политехнического университета. - 2006. - Т. 309. - № 4. C. $123-129$

23. Defects in structure as the sources of the surface charges of kaolinite / Xiaoyan Zhu, Zhichao Zhu, Xinrong Lei, Chunjie Yan // Applied Clay Science. - 2016. - V. 124-125. - P. 127-136.

24. Insight into morphology and structure of different particle sized kaolinites with same origin / Yude Zhang, Qinfu Liu, Jingjing Xiang, Shilong Zhang, R.L. Frost // Journal of Colloid and Interface Science. - 2014. - V. 426. - P. 99-106

25. Madejova J., Gates W.P., Petit S. Ch. 5. IR Spectra of Clay Minerals // Developments in Clay Science. - 2017. - V. 8. - P. 107-149. DOI: 10.1016/B978-0-08-100355-8.00005-9.

26. Characterization and differentiation of kaolinites from selected Czech deposits using infrared spectroscopy and differential thermal analysis / L. Vaculikova, E. Plevova, S. Vallova, I. Koutnik // Acta Geodynamica et Geomaterialia. - 2011. V. 8. - № 1 (161). - P. 59-67.

27. A spectroscopic comparison of selected Chinese kaolinite, coal bearing kaolinite and halloysite - a mid-infrared and near-infrared study / Hongfei Cheng, Jing Yang, Qinfu Liu, Jinshan Zhang, R.L. Frost // Spectrochimica Acta Part A. - 2010. - V. 77. P. 856-861

28. Wilson M.J. Clay mineralogy: spectroscopic and chemical determinative methods. - London: Chapman \& Hall, 1994. - 367 p.

29. Закономерности изменения содержания связанной воды в каолиновой глине при ее сжатии высокими давлениями / В.В. Середин, Н.А. Медведева, А.В. Анюхина, А.В. Андриа- 
нов // Вестник Пермского университета. - 2018. - Т. 17. № 4. - C. 359-369. DOI: 10.17072/ psu.geol.17.4.359

30. Дятлова Е.М., Бобкова Н.М., Сергиевич О.А. ИКспектроскопическое исследование каолинового сырья белорусских месторождений // Проблемы недропользования. 2019. - № 2. - C. 143-149.
31. Влияние давления и гранулометрического состава на энергетическую активность глин / В.В. Середин, А.В. Растегаев, В.И. Галкин, Т.Ю. Паршина, Г.А. Исаева // Инженерная геология. - 2017. - № 4. - С. 62-71. DOI: 10.25296/1993-50562017-4-62-71

Поступила 03.06.2020 г.

\section{Информация об авторах}

Ситева О.С., инженер-геолог, ООО НИППППД «Недра».

Медведева Н.A., кандидат химических наук, доцент кафедры физической химии Пермского государственного национального исследовательского университета.

Середин B.B., доктор геолого-минералогических наук, профессор, заведующий кафедрой инженерной геологии Пермского государственного национального исследовательского университета.

Иванов Д.В., старший преподаватель кафедры фармакологии и фармации Пермского государственного национального исследовательского университета.

Алванян К.A., старший преподаватель кафедры инженерной геологии и охраны недр Пермского государственного национального исследовательского университета. 
UDC 624.131 .412

\title{
INFLUENCE OF PRESSURE ON KAOLINITE STRUCTURE IN FIRE-CLAYS OF THE NIZHNE-UVELSKOE DEPOSIT BY IR SPECTROSCOPY
}

\author{
Olga S. Siteva ${ }^{1}$, \\ sisesin@rambler.ru
}

\author{
Natalia A. Medvedeva², \\ nata-kladova@yandex.ru \\ Valeriy V. Seredin², \\ seredin@nedra.perm.ru

\section{Dmitriy V. Ivanov², dm-psu@yandex.ru} \\ Karine A. Alvanian², \\ karishuta@yandex.ru \\ 1 «Nedra», \\ 13a, Lva Shatrova street, Perm, 614064, Russia. \\ 2 Perm State National Research University, \\ 15, Bukirev street, Perm, 614068, Russia.
}

The research is relevant due to the need to study the structure of kaolin clays in relation to their wide industrial application. Physical and physico-chemical properties of clays change under various technogenic impacts on them. The change is caused by crystalline structure transformation.

The main aim of the research is to study the effect of pressure on the structure of kaolinite.

The object of the research is the kaolin clay of the Nizhne-Uvelskoe deposit of the Chelyabinsk region.

The method of the research is the infrared spectroscopy. Infrared spectra were recorded on an IR Fourier-spectrometer in the range $400 \ldots 3800 \mathrm{~cm}^{-1}$. IR spectrum was processed using Fspec software.

The results of experimental studies showed that the enriched kaolin clay of the Nizhne-Uvelskoe deposit of the Chelyabinsk region, which was not exposed to pressure, is characterized by a partially ordered (defective) structure. Under the influence of pressures from 10 to $650 \mathrm{MPa}$, the clay is characterized by a partially ordered structure, at pressures from 700 to $800 \mathrm{MPa}$ - a poorly ordered and disordered structure. Pressure treatment of kaolin increases the defectiveness of the structure at the packet level. The bonds between Al-OH, Si-O-Al, inner and inner-surface hydroxyls are destroyed, which leads to the displacement of Al from the octahedral and Si from tetrahedral sheets and the formation of «hole» energy centers in the kaolinite crystal lattice. Moreover, the effect of pressure up to $150 \mathrm{MPa}$ on formation of defects in kaolinite is higher than at pressures from 150 to $800 \mathrm{MPa}$. In addition, during the processing of kaolin by pressure, structural defects are formed at the inter packet level due to sliding, rotation and rolling of structural packets between themselves.

Key words:

Fire-clay, deposit, kaolinite, modification, infrared spectroscopy, degree of structure perfection.

\section{REFERENCES}

1. Kukovskiy E.G. Prevrashcheniya sloistykh silikatov [Transformations of layered silicates]. Kiev, Naukova dumka Publ., 1973. $101 \mathrm{p}$.

2. Medvedeva N.A., Siteva O.S., Seredin V.V. Sorption ability of clays exposed to compression. Bulletin of the Perm National Research Polytechnic University. Geology. Oil and gas and mining, 2018 , vol. 18 , no. 2 , pp. 118-128. In Rus. DOI: 10.15593/2224$9923 / 2018.4 .2$

3. Drits V.A. Priroda narusheniya uporyadochennosti v strukturakh nekotorykh sloistykh silikatov [The nature of the disorder in the structures of some layered silicates]. Rentgenografiya mineralnogo syrya, 1966, vol. 5. pp. 94-105.

4. Ovcharenko F.D., Kruglitskiy N.N., Rusko Yu.A., Moroz I.I., Komskaya M.S., Teodorovich Yu.N. Kaoliny Ukrainy [Kaolins of Ukraine]. Kiev, Naukova dumka Publ., 1982. 367 p.

5. Rusko Yu.A. Strukturnye i morfologicheskie razlichiya kaolinita v porodakh kory vyvetrivaniya ukrainskogo shchita [Structural and morphological differences of kaolinite in the rocks of the weathering crust of the Ukrainian shield]. Kaoliny [Kaolins]. Moscow, Nauka Publ., 1974. pp. 95-106.

6. Solotchina E.P., Sukhorukov F.V. O tonkoy kristallicheskoy strukture kaolinitov kory vyvetrivaniya na granitakh [The fine crystal structure kaolinites weathering crust on granites]. Doklady Akademii nauk SSSR, 1979, vol. 244, no. 4. pp. 964-968.

7. Plastinina M.A., Kukovskiy E.G. Stepen sovershenstva kaolinitov po dannym rentgenografii i IK-spektroskopii [The degree of perfection of kaolinites according to $\mathrm{x}$-ray and infrared spectroscopy]. Mineralogicheskiy zhurnal, 1979, vol. 1, no. 2, pp. 67-72.

8. Murray H.H., Lyons S.C. Further correlations of kaolinite crystallinity with chemical and physical properties. Clays Mineralogy, 1960, vol. 8, pp. 11-17.

9. Suraj G., Iyer C.S.P., Rugmini S., Lalithambika M. The effect of micronization on kaolinites and their sorption behavior. Applied Clay Science, 1997, vol. 12, pp. 111-130.

10. Frost R.L., Horváth E., Makó É., Kristóf J. Modification of lowand high-defect kaolinite surfaces: implications for kaolinite mineral processing. Journal of Colloid and Interface Science, 2004, vol. 270 , pp. 337-346.

11. Vyakhirev N.P. Promezhutochnye formy v nepreryvnom ryadu amorfnoe veshchestvo - kaolinit [Intermediate forms in a continuous row amorphous substance - kaolinite]. Rentgenografiya mineralnogo syrya, 1966, vol. 5, pp. 128-131.

12. Plastinina M.A., Kukovskiy E.G., Fedorenko Yu.G., Kadoshnikov V.M. Nekotorye osobennosti proyavleniya nesovershenstva kaolinitov na ikh infrakrasnykh spektrakh pogloshcheniya [Some features of the manifestation of imperfection of kaolinites on their 
infrared absorption spectra]. Mineralogicheskiy sbornik, 1979, vol. 1, no. 33, pp. 27-32.

13. Tarasevich Yu.I., Ovcharenko F.D. Adsorbtsiya na glinistykh mineralakh [Adsorption on clay minerals]. Kiev, Naukova dumka Publ., 1975. $351 \mathrm{p}$.

14. Pentrak M., Madejova J., Komadel P. Acid and alkali treatment of kaolins. Clay Minerals, 2009, vol. 44, pp. 511-523.

15. Seredin V.V., Rastegaev A.V., Medvedeva N.A., Parshina T.Yu. Influence of pressure on the active surface area of clay soil particles. Engineering Geology, 2017, no. 3, pp. 18-27. In Rus. DOI: 10.25296/1993-5056-2017-3-18-27.

16. Kubekova Sh.N., Tanau A. Ispolzovanie metoda IK-spektroskopii dlya opredeleniya molekulyarnogo sostava neorganicheskikh veshchestv [Use of IR spectroscopy for determining the molecular composition of inorganic substances]. Almaty, KazNTU by K.I. Satpaeva, 2014. 17 p.

17. Papko L.F., Kravchuk A.P. Fiziko-khimicheskie metody issledovaniva neorganicheskikh veshchestv $i$ materialov [Physicochemical methods for the study of inorganic substances and materials]. Minsk, BGTU Publ., 2013. 95 p.

18. Nechiporenko A.P., Orekhova S.M., Plotnikova L.V., Glazacheva E.N., Volkova K.V., Uspenskaya M.V. Spetsializirovanny praktikum po fiziko-khimicheskim metodam analiza: teoriya $i$ praktika. Ch. II [Specialized workshop on physico-chemical methods of analysis: theory and practice. P. II]. St-Petersburg, ITMO University Publ., 2016. 181 p.

19. Chukanov N.V. Infrared spectra of mineral species. Dordrecht, Springer, 2014. $1726 \mathrm{p}$.

20. Plyusnina I.I. Infrakrasnye spektry mineralov [Infrared spectra of minerals]. Moscow, Moscow University Publ., 1976. 190 p.

21. Uorrel U. Gliny i keramicheskoe syre [Clays and ceramic raw materials]. Moscow, Mir Publ., 1978. 241 p.

22. Zavorin A.S., Buvakov K.V., Gladkov V.E., Krasilnikova L.G. Identification of the mineral macrocomponents of the inorganic part of the Kansk-Achinsk coal. Bulletin of the Tomsk Polytechnic University, 2006, vol. 309, no. 4, pp. 123-129.

23. Xiaoyan Zhu, Zhichao Zhu, Xinrong Lei, Chunjie Yan. Defects in structure as the sources of the surface charges of kaolinite. Applied Clay Science, 2016, vol. 124-125, pp. 127-136.

24. Yude Zhang, Qinfu Liu, Jingjing Xiang, Shilong Zhang, Frost R.L. Insight into morphology and structure of different particle sized kaolinites with same origin. Journal of Colloid and Interface Science, 2014, vol. 426, pp. 99-106.

25. Madejova J., Gates W.P., Petit S. Ch. 5. IR Spectra of Clay Minerals. Developments in Clay Science, 2017, vol. 8, pp. 107-149. DOI: 10.1016/B978-0-08-100355-8.00005-9.

26. Vaculikova L., Plevova E., Vallova S., Koutnik I. Characterization and differentiation of kaolinites from selected Czech deposits using infrared spectroscopy and differential thermal analysis. Acta Geodynamica et Geomaterialia, 2011, vol. 8, no. 1 (161), pp. 59-67.

27. Hongfei Cheng, Jing Yang, Qinfu Liu, Jinshan Zhang, Frost R.L. A spectroscopic comparison of selected Chinese kaolinite, coal bearing kaolinite and halloysite - a mid-infrared and near-infrared study. Spectrochimica Acta, 2010, vol. 77, pp. 856-861.

28. Wilson M.J. Clay mineralogy: spectroscopic and chemical determinative methods. London, Chapman \& Hall, 1994. 367 p.

29. Seredin V.V., Rastegaev A.V., Galkin V.I., Isaeva G.A., Parshina T.Yu. Changes of energy potential on clay particle surfaces at high pressures. Applied Clay Science, 2018, vol. 155, pp. 8-14. DOI: 10.1016/j.clay.2017.12.042

30. Dyatlova E.M., Bobkova N.M., Sergievich O.A. IR-study of kaolin materials of Belarusian deposits. Problem of the subsoil use, 2019, no. 2, pp. 143-149. In Rus.

31. Seredin V.V., Rastegaev A.V., Galkin V.I., Parshina T.Yu., Isaeva G.A. Influence of pressure and particle-size composition on energy activity of clays. Engineering Geology, 2017, no. 4, pp. 62-71. In Rus. DOI: 10.25296/1993-5056-2017-4-62-71.

Received: 3 June 2020.

\section{Information about the authors}

Olga S. Siteva, geologist, «Nedra».

Natalia A. Medvedeva, Cand. Sc., associate professor, Perm State National Research University.

Valeriy V. Seredin, Dr. Sc., professor, head of the Department of Engineering Geology, Perm State National Research University.

Dmitriy V. Ivanov, lecturer, Perm State National Research University.

Karine A. Alvanian, senior lecturer, Perm State National Research University. 